Revista de Derecho

de la Pontificia Universidad Católica de Valparaíso LV (Valparaíso, Chile, 2do semestre de 2020)

[pp. 131-155]

\title{
¿Qué ACTOS PUEDEN CONSTITUIR UN ATAQUE CONTRA UNA POBLACIÓN CIVIL EN LA TIPIFICACIÓN DE CRÍMENES DE LESA HUMANIDAD DE LA LEY No 20.357?
}

[Which Acts Count as Part of an Attack Against a Civilian Population in the Legal Description of Crimes Against Humanity Contained in the Act No. 20.357?]

\section{Claudia Marcela CÁRDEnAS ArAVENA* \\ Universidad de Chile, Chile}

\section{Resumen}

El trabajo busca ofrecer una respuesta fundada a una interrogante que surge ante la posibilidad de iniciar investigaciones por crímenes de lesa humanidad en Chile, que, como otros países, ha adoptado una implementación modificatoria de los crímenes de lesa humanidad, sin que la noción de ataque contra una población civil se defina expresamente en la ley de implementación: ¿qué actos cuentan para determinar la existencia de un ataque contra una población civil de acuerdo a la Ley No 20.357? Esta cuestión se analiza aplicando los criterios generales de interpretación y tomando como referencia al derecho chileno. Como resultado principal se afirma que para que exista un ataque típico, deben probarse uno o más actos de los descritos en el artículo 7.1 del Estatuto de Roma, que (si son varios, en conjunto) se dirija(n) contra una población civil o afecte(n) a un número considerable de personas, y que responda(n) a una política ya sea de un Estado; de sus agentes; de grupos armados organizados que, bajo la dirección de un mando responsable, ejerzan sobre algún territorio un control que les permita realizar operaciones militares; o de grupos organizados que detenten un poder de hecho que favorezca la impunidad de sus actos.

\section{Abstract}

The main objective of the article is to offer an informed answer to the question concerning which acts are relevant to determine the existence of an attack directed against any civilian population as an element of crimes against humanity according to Chilean Act No 20,357, as in the matter of crimes against humanity Chile has adopted a modified incorporation of the Rome Statute, and the meaning of the expression "ataque contra una población civil” is not explicitly defined. The methodology used in order to analyse this question consists of an application of the general standards of legal interpretation. As the main result, it is affirmed that in order for a relevant attack to exist, one or more acts described in Article 7.1 of the Rome Statute have to be proven, which are, as a whole, directed against a civilian population or affect a considerable number of persons. Furthermore, the act(s) shall respond to a policy from a state, or from its agents, or from organised armed groups which, under responsible command, exercise territorial control that enable them to carry out military operations, or from organised groups which hold a de-facto power that favours the impunity of their deeds.

* Dr. Iur., profesora asociada del Departamento de Ciencias Penales de la Universidad de Chile. Dirección electrónica: ccardenas@derecho.uchile.cl 
Palabras clave

Ataque contra una población civil

- Chile - crímenes de lesa humanidad - implementación modificatoria del Estatuto de Roma.

\section{KeY Words}

Attack directed against any civilian population - Chile - crimes against humanity - modified incorporation.

Recibido el 19 de noviembre de 2020 y aceptado el 1 de marzo de 2021

\section{INTRODUCCIÓN}

A partir de 2002, con la entrada en vigor del Estatuto de Roma, un número considerable de Estados se han dado a la tarea de implementar los crímenes de lesa humanidad en su derecho interno, adoptando para ello distintas modalidades de implementación ${ }^{1}$. Siendo Chile un país cuyo sistema jurídico es de raigambre continental, no fue sorpresivo que al igual que Alemania y España, que suelen servirle como referencia en materias penales, optara por una implementación modificatoria ${ }^{2}$; en la que parte de las diferencias respecto del tratado que se implementa son reconocibles en el listado de conductas que en el derecho interno pueden constituir crímenes de lesa humanidad; conservándose, por otra parte, la exigencia general de que, para ser subsumibles como tales, han de cometerse como parte de un ataque generalizado o sistemático contra una población civil ${ }^{3}$. Estos ordenamientos también comparten que no llega a definirse qué actos cuentan para constituir tal ataque. Tal renuncia puede pasar desapercibida si en el contexto cuya subsunción se plantea se han cometido solamente actos imputables como posibles crímenes de lesa humanidad tanto en el derecho internacional como en el derecho interno (así sucede, a saber, con el homicidio) cometidos contra personas en razón de su pertenencia a un colectivo diferenciable del resto de la población. En cambio, entender sus efectos cobra relevancia práctica si se plantea la aplicación del tipo a contextos donde también hay mérito para investigar si han ocurrido actos inhumanos del derecho internacional, que en cambio no correspondan a conductas que podrían llegar a calificarse como crímenes de lesa humani-

${ }^{1}$ Werle, Gerhard - Jessberger, Florian, Tratado de derecho penal internacional (3a edición, Valencia, Tirant lo Blanch, 2017) pp. 266 y ss. Diversas legislaciones de implementación pueden consultarse en https://www.legal-tools.org.

${ }^{2}$ Cárdenas Aravena, Claudia Marcela, Los crímenes del Estatuto de la Corte Penal Internacional en el derecho chileno, necesidad de una implementación, en Politica Criminal No 2 (2006), p. 14; WerLe, Gerhard, Konturen enies deutschen Völkerstrafrechts, en JuristenZeitung (18 2001), pp. 887 y ss.

${ }^{3}$ Vid. artículos 1.1 y 3 a 9 de la Ley No 20.357, Parágrafo 7 del Código de derecho penal internacional (Völkerstrafgesetzbuch) alemán y artículo 607 bis del Código Penal español. 
dad de acuerdo al derecho interno (así, actos de persecución u otros actos inhumanos que no estén específicamente descritos); y la calificación del contexto como uno de ataque típico depende en alguna medida de que se compruebe la comisión de estos actos.

Algo análogo sucederá, tomando como referencia al tipo de la Ley No 20.357, si concurren actos que afecten a un número considerable de personas, las que sin embargo no sean susceptibles de ser caracterizadas como una colectividad separada del resto de la población por alguna característica común que las hace ser objeto del ataque. ¿Cuentan esos actos como eventualmente constitutivos de un ataque contra una población civil de acuerdo a la Ley No 20.357? Tener claridad al respecto resulta relevante de cara a un escenario en el que se hace necesario evaluar la posibilidad de investigar de acuerdo a las disposiciones de la Ley No 20.357, para lo cual, en materia de crímenes de lesa humanidad, aparte de dirigir la investigación a conductas individuales (artículos 3 al 9 de la Ley No 20.357), ha de poder determinase si existe un ataque típico, lo que requiere saber qué clase de conductas se cuentan para constituirlo.

A continuación, se procurará dar respuesta fundada a la interrogante de qué actos pueden constituir un ataque contra una población civil en la tipificación de crímenes de lesa humanidad de la Ley No 20.357. Para eso, se tratará la estructura de los crímenes de lesa humanidad en lo necesario para entender el foco de este examen (II.), se abordará el carácter de implementación modificatoria de la tipificación chilena de los crímenes de lesa humanidad y las consecuencias que de ello se siguen para su interpretación (III.), para luego abordar específicamente la interpretación del ataque contra una población civil en la Ley No 20.357 (IV.) recapitular (V.) y explicar las consecuencias que se siguen de la interpretación propuesta (VI.).

\section{ESTRUCTURA DE LOS CRÍMENES DE LESA HUMANIDAD Y FOCO DE ESTE}

\section{EXAMEN}

Los crímenes de lesa humanidad tienen una estructura bipartita, consistente en una serie de requisitos comunes que deben concurrir siempre que se utilice esa calificación y otra serie de requisitos contingentes a las conductas concretas que se imputen como crímenes de lesa humanidad. En la nomenclatura del derecho internacional, esto se traduce en que deben concurrir un hecho global junto a uno o más hechos individuales ${ }^{4}$. Dicho

${ }^{4}$ Werle, Gerhard - Jessberger, Florian, cit. (n. 1), pp. 554 y ss.; SAFFerling, Christoph, Internationales Strafrecht (Springer, Heidelberg, 2011), pp. 186 y ss. 
de otro modo, para que haya crímenes de lesa humanidad se requiere de la comisión de ciertas conductas insertas en un determinado contexto.

En la Ley No 20.357, esta estructura bipartita se mantiene, manifestándose incluso en que el hecho global y los hechos individuales se tipifican en artículos distintos: así, al primero se dedican los artículos 1 y 2; en tanto que los segundos se tipifican en los artículos 3 al 9 de la Ley No 20.357. Lo anterior implica que siempre debe concurrir un ataque generalizado o sistemático contra una población civil que responda a una política de cierto origen; en tanto que deben concurrir también, en el caso concreto, los requisitos objetivos y subjetivos de la(s) conducta(s) que en concreto se quiera imputar (así, los de homicidio, tortura, violación, desaparición forzada de personas, etc.); además de cometerse cada una de estas conductas como parte del ataque (artículo 1 No 1 de la Ley No 20.357).

Es importante distinguir el plano del ataque, por una parte, y el de las conductas a imputar, por otra, para no confundir el alcance de cada requisito. Así, por ejemplo, lo que debe ser susceptible de ser caracterizado como generalizado o sistemático es el ataque, y no necesariamente la conducta que en concreto se vaya a imputar como crimen de lesa humanidad'.

Para responder la interrogante que guía este trabajo es relevante sobre todo la interpretación del hecho global en la Ley No 20.357; y en particular el elemento de contexto, consistente en un ataque contra una población civil, que para ser típico ha de ser ya sea generalizado o sistemático.

\section{EL CARÁCTER DE IMPLEMENTACIÓN MODIFICATORIA DE LA TIPIFICACIÓN} DE CRÍMENES DE LESA HUMANIDAD EN LA LEY No 20.357 y SUS

CONSECUENCIAS

\section{La tipificación de crimenes de lesa humanidad en la Ley No 20.357} como implementación modificatoria

La legislación que se dan los Estados buscando cumplir con obligaciones adquiridas en virtud del derecho internacional, o simplemente adecuándola a él aun en ausencia de una obligación estricta de hacerlo recibe, en general, el nombre de legislación de implementación. En el caso del Estatuto de Roma de la Corte Penal Internacional, puede advertirse una tendencia estatal a darse legislaciones de implementación, sobre todo en lo relativo a los delitos sobre los que esta Corte tiene competencia material, desde inicios del siglo XXI. Entre las decisiones más relevantes en materia de implementación de tratados en el derecho interno están la

${ }^{5}$ De lo contrario, no habría posibilidad de aplicar la circunstancia agravante especial del artículo 39 de la ley No 20.357. 
de implementar o no, la de dónde (en qué cuerpo normativo) hacerlo, y la de cómo hacerlo (con una remisión o una copia, o modificando ciertos elementos). En el caso de la implementación del Estatuto de Roma, Chile optó por una implementación modificatoria en una ley especial, la Ley No 20.357 de 18 de julio de $2009^{6}$.

El hecho de que se trate de una implementación modificatoria implica que los poderes colegisladores chilenos estimaron pertinente variar la descripción de algunos elementos del delito respecto de como se encuentran en el Estatuto de Roma. Esto es perfectamente lícito y hasta usual en materia de crímenes de lesa humanidad, en los países con sistemas de raigambre continental $^{7}$, que buscan adecuar el tipo del derecho internacional a las exigencias que sus sistemas prevén por el modo en que han implementado el principio de legalidad en sus ordenamientos internos ${ }^{8}$. Así, en Chile, las conductas punibles como crímenes de lesa humanidad con arreglo al derecho internacional (los denominados actos inhumanos), en general han servido de fuente para la tipificación de los hechos individuales en los artículos 3 al 9 de la Ley No 20.357, pero no se trata de listados idénticos, tanto porque hay actos inhumanos del derecho internacional que no están descritos en la ley chilena (como la persecución y al apartheid), como porque las remisiones al Código penal hacen que conductas con el mismo nomen iuris hayan de interpretarse de manera distinta (como ocurre con la violación) $)^{9}$.

${ }^{6}$ Ley No 20.359, tipifica crímenes de lesa humanidad, de genocidio y crímenes y delitos de guerra. Diario Oficial, 18 de julio de 2009. Sobre implementación, Werle, Gerhard - Jessberger, Florian, cit. (n. 1), p. 269.

${ }^{7}$ A saber, puede consultarse el artículo 607 bis del Código penal español y el parágrafo 7 del Código de Derecho Penal Internacional alemán.

${ }^{8}$ Werle, Gerhard, Das Völkerstrafgesetzbuch, en JuristenZeitung (15/16 2002), p. 730 .

${ }^{9}$ Una revisión para cada forma de acto inhumano se encuentra en CÁRDENAS Aravena, Claudia Marcela, Los crimenes de lesa humanidad en el derecho chileno y en el derecho internacional. Sus requisitos comunes, además de referencias a los actos inhumanos en particular, en Revista de Derecho, Valdivia (2014), pp. 180 y ss. Sobre la violación como crimen de lesa humanidad pueden revisarse los Elementos de los Crímenes para el art. 7.1 g)-1; De Brouwer, Anne Marie, Supranational Prosecution of Sexual Violence. The ICC and the Practice of the ICTY and the ICTR (Intersentia, Antwerpen-Oxford), pp. 103 y ss.; Hall, Christopher Keith - Powderly, Joseph HAYES, NiAMH, Article 7- 'Rape ... or any other form of sexual violence of comparable gravity', en: Triffterer, Otto - Ambos, Kai (editores), The Rome Statute of the International Criminal Court, A Commentary ( $3^{a}$ edición, Munich, Beck, Nomos, Hart, 2016), pp. 235-242. Acerca de la comisión de otros actos inhumanos que grandes sufrimientos o atentado gravemente contra la integridad física o la salud mental o física , Hall, Christopher Keith - Stahn, Carsten, Article 7- 'Other 
En esta materia el Estado es libre de darse la legislación penal que estime más pertinente, sin perjuicio, claro, de que eso no afecta la responsabilidad penal que surge del derecho internacional ${ }^{10}$. Habría que distinguir entonces: cada Estado aplicará su legislación, con las particularidades que haya decidido darse, tanto en materia de tipos como de responsabilidad, mientras que la responsabilidad penal internacional continuará rigiéndose por el derecho penal internacional en el sentido de que no se extingue porque legislaciones nacionales eventualmente no abarquen algunos de sus supuestos.

\section{Consecuencias que se siguen del carácter de implementación modificatoria} para la interpretación del tipo

En las implementaciones modificatorias de tratados es usual que se usen palabras o expresiones que se encuentran en el tratado que se está implementando y al mismo tiempo se empleen palabras o expresiones con un sentido jurídico propio del sistema en el que la ley se inserta.

De acuerdo a las reglas generales de interpretación, a las expresiones de una ley que se toman de los tratados corresponderá darles el significado que tienen en el derecho internacional de donde provienen, "a menos que aparezca claramente que se ha tomado en un sentido diverso" (artículo 21 de Código civil) ${ }^{11}$. Esto último sucede en los casos en los que los poderes colegisladores expresamente definen ciertos términos. En lo que, en cambio, no esté definido, tratándose de términos técnicos, ha de dárseles el significado propio de la disciplina de la cual provienen. En el caso que nos convoca, esa disciplina es el derecho penal internacional ${ }^{12}$.

En concreto, en lo que interesa para abordar la pregunta que guía este texto, para interpretar el requisito común del artículo 1.1 de la Ley No

Ihnuman Acts', en: Triffterer, Otto - Ambos, Kai (editores), cit. (n. 9), pp. 206219; Bassiouni, M. Cherif, Crimes Against Humanity. Historical Evolution and Contemporary Application (Cambridge University Press, Cambridge), pp. 405 y ss. Respecto del crimen de persecución, Bassiouni, M. Cherif, cit. (n. 9), pp. 396 y ss.

${ }^{10}$ Cárdenas Aravena, Claudia Marcela, Los crimenes del Estatuto, cit. (n. 2), p. 5 yss.

${ }^{11}$ Código Civil, en el título sobre interpretación de la ley Artículo 21.- Las palabras técnicas de toda ciencia o arte se tomarán en el sentido que les den los que profesan la misma ciencia o arte; a menos que aparezca claramente que se han tomado en sentido diverso.

${ }^{12}$ Sobre la relevancia de esta clase de términos en la interpretación de la ley No 20.357 CÁrdenas Aravena, Claudia Marcela, La aplicabilidad del derecho internacional por tribunales chilenos para interpretar la ley $N^{\circ} 20.357$, en Revista de Derecho, Coquimbo (2013), pp. 130 y ss.; Werle, Gerhad - Jessberger, Florian, cit. (n. 1), pp. 272-273; WerLE, Gerhard, Völkerstrafgesetzbuch, cit. (n.8), p. 734. 
20.357, consistente en que "el acto sea cometido como parte de un ataque generalizado o sistemático contra una población civil”, como un requisito para que los actos descritos entre los artículos 3 y 9 de la Ley No 20.357 constituyan crímenes de lesa humanidad, dicha ley entrega algunas definiciones legales que debieran respetarse como tales al interpretar sus demás disposiciones, en tanto que lo que ellas no cubren ha de interpretarse de acuerdo al sentido técnico del término "ataque" para los crímenes de lesa humanidad en el derecho penal internacional ${ }^{13}$.

\section{INTERPRETACIÓN DE LA EXPRESIÓN “ATAQUE CONTRA UNA POBLACIÓN CIVIL” EN EL ARTíCULO 1.1 DE LA LEY No 20.357, CON ESPECIAL} REFERENCIA A LAS CONDUCTAS SUSCEPTIBLES DE SER PARTE CONSTITUTIVA DE UN ATAQUE

Para llevar a cabo la interpretación propuesta, de acuerdo a lo explicado, es procedente iniciar distinguiendo entre lo que la Ley No 20.357 define expresamente (1.), de aquellos términos cuyo sentido, por no contar con definición legal, habrá que determinar de acuerdo con el derecho penal internacional, en lo que no resulte incompatible con las decisiones de los poderes colegisladores chilenos (2.).

\section{Las definiciones de la Ley No 20.357}

Los poderes colegisladores chilenos se pronunciaron expresamente respecto de cuatro puntos relevantes para la definición de la expresión "ataque contra una población civil" en la Ley No 20.357. Se trata de la cantidad de actos que se requieren para que exista un ataque (a)), su objeto (b)), la relación entre la política y el ataque (c)), y la fuente de la cual puede emanar la política $(\mathrm{d})$ ).

a) Cuántos actos bastan para constituir un ataque

El primer numeral del artículo 2 de la Ley No 20.357 explicita que el ataque puede estar constituido por un solo acto (y será ese un supuesto de ataque generalizado). De este modo, cede el requisito estatutario de

${ }^{13}$ Que es distinta de la noción de ataque para el derecho internacional humanitario. Vid., a saber, Hall, Christopher Keith - Aмвоs, Kai, Article 7- "Attack", en: Triffterer, Otto - Ambos, Kai (editores), cit. (n. 9), pp. 242 y ss.; Werle, Gerhard - Jessberger, Florian, cit. (n. 1), p. 555 y ss. De hecho, en el preámbulo de los Elementos de los Crímenes para el artículo 7 del Estatuto de Roma, en su párrafo 3 , se especifica que el ataque en los crímenes de lesa humanidad no necesita ser un ataque militar. 
multiplicidad de actos (artículo 7.2 a) del Estatuto de Roma) ante la disposición expresa de la Ley No 20.357.

La del acto único es una hipótesis aceptada en la doctrina del derecho penal internacional, sobre todo desde el atentado contra las torres gemelas en Nueva York el año 2001, que cobraron un número aproximado de 2600 víctimas en un país de aproximadamente 285.000 .000 personas ${ }^{14}$, por lo que se trata de una desviación respecto del Estatuto de Roma de la Corte Penal Internacional más que respecto del derecho internacional en su conjunto.

\section{b) Objeto del ataque}

La ley chilena no define la expresión "ataque contra una población civil" usada en su artículo $1.1^{15}$, sin perjuicio de que sí define tanto "ataque generalizado" como "ataque sistemático" en el artículo 2 de la Ley No 20.357, en los términos siguientes: Artículo $2^{\circ}$.- Para efectos de lo dispuesto en el artículo precedente, se entenderá: $1^{\circ}$. Por 'ataque generalizado', un mismo acto o varios actos simultáneos o inmediatamente sucesivos, que afectan o son dirigidos a un número considerable de personas, y $2^{\circ}$. Por 'ataque sistemático', una serie de actos sucesivos que se extienden por un cierto periodo de tiempo y que afectan o son dirigidos a un número considerable de personas.

Lo expresado en este artículo da cuenta de decisiones legislativas entre las que se cuenta que para que exista un ataque en materia de crímenes de lesa humanidad en la Ley No 20.357, el o los actos que lo integren han de dirigirse contra un número considerable de personas, o, alternativamente, deben afectarlas. Ambas hipótesis han de tenerse en cuenta al interpretar la expresión "contra una población civil" en el artículo 1 de la Ley No 20.357, a fin de hacerla compatible con ambas, sobre todo porque las definiciones se entregan justamente "para efectos de lo dispuesto en el artículo precedente", que es el artículo 1 . Entonces, si bien el artículo 1.1 mantiene el enunciado "contra una población civil", tomado textualmente del derecho internacional, para interpretar esa expresión, es necesario considerar lo dispuesto en el artículo 2 de la Ley No 20.357. Ese artículo, si bien se dedica a definir a las características del ataque, no las define en abstracto, como "sistematicidad" o "generalidad", sino que vinculadas a un ataque. Así, al definir ataque generalizado por una parte y ataque sistemático por

${ }^{14}$ Bassiouni, M. Cherif, cit. (n. 9), p. 30; Werle, Gerhad - Jessberger, Florian, cit. (n. 1), p. 480.

${ }^{15}$ Artículo $1^{\circ}$.- Constituyen crimenes de lesa humanidad los actos señalados en el presente párrafo, cuando en su comisión concurran las siguientes circunstancias:

${ }^{1 .}$ Que el acto sea cometido como parte de un ataque generalizado o sistemático contra una población civil. 
otra, habrá de entenderse que lo que sea común a ambas definiciones será un elemento de la noción general de ataque típico en la Ley No 20.357, en materia de crímenes de lesa humanidad.

En el artículo 2 de la Ley No 20.357, lo que es común a ambas clases de ataque es que los actos que lo constituyen han de ser dirigidos a un número considerable de personas, o, alternativamente, han de afectar a un número considerable de personas.

Mediante las hipótesis alternativas descritas, se agrega una posibilidad respecto a lo establecido en el Estatuto de Roma, que esta vez importa una variación respecto del derecho internacional en su conjunto, y no solo respecto del texto de ese tratado. Allí existe como exigencia típica que el ataque tenga a una población civil como objeto, definiendo a la población civil como un colectivo que se distingue del resto de la población por una característica que le hace ser objeto no incidental del ataque ${ }^{16}$. Sin perjuicio

${ }^{16}$ Vid. Corte Penal Internacional, Sala de Cuestiones Preliminares II, Decision Pursuant to Article 61(7)(a) and (b) of the Rome Statute on the Charges of the Prosecutor Against Jean-Pierre Bemba Gombo, de fecha 15 de julio de 2009, No ICC-01/05-01/08, pfo. 76; Corte Penal Internacional, Sala de Cuestiones Preliminares III, Corrigendum to "Decision Pursuant to Article 15 of the Rome Statute on the Authorisation of an Investigation into the Situation in the Republic of Côte d'Ivoire", de fecha 15 de noviembre de 2011, No ICC-02/11, pfo. 33, con más referencias; Corte Penal Internacional, Sala de Cuestiones Preliminares III, Decision on the Prosecutor's Application Pursuant to Article 58 for a warrant of arrest against Laurent Koudou Gbagbo, de fecha 30 de noviembre de 2011, No ICC02/11-01/11, pfo. 30; Corte Penal Internacional, Sala de Cuestiones Preliminares II, Decision on the Confirmation of Charges Pursuant to Article 61(7)(a) and (b) of the Rome Statute, de fecha 23 de enero de 2012, No ICC-01/09-01/11, pfo. 109; Corte Penal Internacional, Sala de Cuestiones Preliminares II, Judgment pursuant to article 74 of the Statute Katanga, de fecha 7 de marzo de 2014, No ICC-01/0401/07, pfo. 1105, con más referencias; Corte Penal Internacional, Sala de Cuestiones Preliminares III, Judgment pursuant to article 74 of the Statute, de fecha 21 de marzo de 2016, No ICC-01/05-01/08, pfo. 154; Corte Penal Internacional, Sala de Cuestiones Preliminares III, Public Redacted Version of "Public Redacted Version of "Decision Pursuant to Article 15 of the Rome Statute on the Authorization of an Investigation into the Situation in the Republic of Burundi", de fecha 9 de noviembre de 2017, No ICC-01/17-X-9-US-Exp, 25 October 2017, pfo. 32; Corte Penal Internacional, Sala de Cuestiones Preliminares I, Decision on the Prosecutor's Application for the Issuance of a Warrant of Arrest for Al Hassan Ag Abdoul Aziz Ag Mohamed Ag Mahmoud, de fecha 22 de mayo de 2018, No ICC-01/12-01/18, pfo. 45 ; Corte Penal Internacional, Sala de Cuestiones Preliminares IV, Judgment Bosco Ntaganda, de fecha 8 de julio de 2019, No ICC-01/04-02/06, pfo. 668; Corte Penal Internacional, Sala de Cuestiones Preliminares III, Decision Pursuant to Article 15 of the Rome Statute on the Authorisation of an Investigation into the Situation in the People's Republic of Bangladesh/Republic of the Union of Myanmar, de fecha 14 
de ello, cuando se cometen crímenes de lesa humanidad en situaciones de conflicto armado, ha de recurrirse también a los criterios del ius in bello, aplicable, en general, en esa clase de conflictos ${ }^{17}$. Por cierto, la población, en cuanto es un colectivo, está compuesta por un número considerable de personas ${ }^{18}$.

Teniendo a la vista lo reseñado, cada vez que se cumpla la hipótesis

de noviembre de 2019, No ICC-01/19, pfo. 63. Crítico sobre este criterio (aplicado en otra jurisdicción) se ha mostrado Eвое-Osuj, Chile, Crimes Against Humanity: Directing Attacks Against A Civilian Population, en African Journal of Legal Studies (2008). pp. 118 y ss.

${ }^{17}$ Corte Penal Internacional, Sala de Cuestiones Preliminares II, Decision Pursuant to Article 61(7)(a) and (b) of the Rome Statute on the Charges of the Prosecutor Against Jean-Pierre Bemba Gombo, de fecha 15 de julio de 2009, No ICC-01/05-01/08, pfo. 78; con más referencias; Corte Penal Internacional, Sala de Cuestiones Preliminares III, Corrigendum to "Decision Pursuant to Article 15 of the Rome Statute on the Authorisation of an Investigation into the Situation in the Republic of Côte d'Ivoire", de fecha 15 de noviembre de 2011, No ICC-02/11, pfo. 33, con más referencias; Corte Penal Internacional, Sala de Cuestiones Preliminares II, Decision on the Confirmation of Charges Pursuant to Article 61(7)(a) and (b) of the Rome Statute, de fecha 23 de enero de 2012, No ICC-01/09-01/11, pfo. 109; Corte Penal Internacional, Sala de Cuestiones Preliminares II, Judgment pursuant to article 74 of the Statute Katanga, de fecha 7 de marzo de 2014, No ICC-01/0401/07, pfo. 1102; Corte Penal Internacional, Sala de Cuestiones Preliminares III, Judgment pursuant to article 74 of the Statute, de fecha 21 de marzo de 2016, No ICC-01/05-01/08, pfo. 152; Corte Penal Internacional, Sala de Cuestiones Preliminares III, Public Redacted Version of "Public Redacted Version of "Decision Pursuant to Article 15 of the Rome Statute on the Authorization of an Investigation into the Situation in the Republic of Burundi”, de fecha 9 de noviembre de 2017, No ICC-01/17-X-9-US-Exp, 25 October 2017, pfo. 32; Corte Penal Internacional, Sala de Cuestiones Preliminares I, Decision on the Prosecutor's Application for the Issuance of a Warrant of Arrest for Al Hassan Ag Abdoul Aziz Ag Mohamed Ag Mahmoud, de fecha 22 de mayo de 2018, No ICC-01/12-01/18, pfo. 45 ; Corte Penal Internacional, Sala de Cuestiones Preliminares III, Decision Pursuant to Article 15 of the Rome Statute on the Authorisation of an Investigation into the Situation in the People's Republic of Bangladesh/Republic of the Union of Myanmar, de fecha 14 de noviembre de 2019, No ICC-01/19, pfo. 63. Se manifiestan a favor una definición que no dependa de esa rama del derecho, a saber, Alija Fernández, Rosa Ana - Saura Estapà, Jaume, Towards a Single and Comprehensive Notion of 'Civilian Population' in Crimes against Humanity, en International Criminal Law Review vol. 16 (2016), pp. 1 y ss.; SADAT, Leila Nadya, Putting Peacetime First: Crimes against Humanity and the Civilian Population Requirement, en Emory International Law Review vol. 31 (2017), pp. 197 y ss.

${ }^{18}$ En la misma línea, Bassiouni señalaba que lo que se requiere es que la acción o la política se dirijan contra un grupo identificable de civiles. Bassiouni, M. Cherif, cit. (n. 9), p. 21. 
de que el o los actos se dirige(n) contra una población civil en el sentido del derecho internacional relativo a los crímenes de lesa humanidad, se cumplirá con la variante de que se actúe contra un número considerable de personas. Sin embargo, la Ley No 20.357 prevé una variante típica adicional, consistente en que el ataque afecte a un número considerable de personas. Para dar a esta variante un contenido distinto del de la anterior, como demanda el uso de la conjunción disyuntiva "o" en el texto de la ley, es menester que para determinar si el ataque afecta o ha afectado a un número considerable de personas no se atienda ya a la dirección que se ha dado a el o los actos, sino a los efectos que él o ellos provocan. Si ellos se traducen en la afectación de un número considerable de personas se satisfará la descripción, sin importar si todo o parte de ese número fueron objeto incidental del ataque.

En general, de acuerdo al derecho internacional relativo a los crímenes de lesa humanidad, para determinar que una población civil es objeto de un ataque, no se requiere que uno o más actos inhumanos alcancen a cada uno de los individuos que conforman el grupo, sino solo que los actos se dirijan contra el grupo que -por alguna característica que distingue a sus miembros- conforma una población civil. En cambio, en la variante que requiere afectar a un número considerable de personas tal afectación solo resulta compatible con que el o los actos inhumanos les alcancen, como una forma de distinguir ambos supuestos.

Atendiendo a lo explicado en este apartado, la voz "población civil" en la Ley No 20.357 ha de interpretarse de manera más amplia de lo que es corriente hacerlo en el derecho internacional relativo a los crímenes de lesa humanidad, pues no solo incluye a un grupo de personas identificable como objeto de un ataque por ciertas características que les unen, distinguiéndoles del resto de la población, sino que también puede constituirlo cualquier cantidad considerable de personas que se vean afectadas por uno o más actos de los que constituyen el ataque. Siendo esta una decisión expresa de nuestros poderes colegisladores, ella ha de primar al aplicar la Ley No 20.357.

c) La relación entre la política y el ataque (artículo 1.2 de la Ley $N^{o}$ 20.357)

El artículo 1.2 de la Ley No 20.357 dispone que el ataque debe responder a una política.

La voz responder implica reaccionar. Se busca entonces que el ataque sea una reacción a la política. El término "responder", si bien como tal no está tomado desde el derecho internacional sobre crímenes de lesa humanidad, sí es plenamente compatible con la relación que de acuerdo a este 
ha de haber entre la política y el ataque. El artículo 7.2 a) del Estatuto de Roma, explicita dos opciones de relación entre los actos y la política que implica la comisión de actos inhumanos: que los actos se lleven adelante de conformidad con ella o que los actos se lleven a cabo para promoverla. Ambas variaciones se ven abarcadas por la expresión "responder" que usa la Ley No 20.357.

También del derecho internacional se sigue que si el ataque está constituido por multiplicidad de actos, ha de poder determinarse que ellos se ha llevado a cabo dentro de una línea de conducta, de modo tal que esa línea de conducta es la que se entiende como tal en relación con la política. Esto quiere decir que sean comprensibles como parte de un mismo fenómeno, que obedezcan a una cierta lógica común. Solo entonces se considerará que los actos, así vinculados, con forman un ataque. Este vínculo puede entenderse implementado en la Ley No 20.357 con el requisito de que el ataque -conformado de acuerdo a ella por uno o varios actos- responda a una política.

\section{d) La fuente de la que puede emanar la politica (artículo 1.2 de la Ley} No 20.357)

De acuerdo con el artículo 1.2 de la Ley No 20.357, la política puede emanar ya sea i) de un Estado o ii) de agentes del Estado; iii) de grupos armados organizados que, bajo la dirección de un mando responsable, ejerzan sobre algún territorio un control tal que les permita realizar operaciones militares; $\mathrm{y}$ iv) grupos organizados que detenten un poder de hecho tal que favorezca la impunidad de sus actos.

La existencia de una política estatal es la hipótesis más clásica en materia de crímenes de lesa humanidad. En el derecho penal internacional, se entiende que ella puede emanar ya sea de la cúpula del Estado o de alguna autoridad regional o local, siendo todos los anteriores supuestos de política estatal ${ }^{19}$.

La Ley No 20.357 entiende como un supuesto distinto, unido al del

${ }^{19}$ Corte Penal Internacional, Sala de Cuestiones Preliminares II, Decision Pursuant to Article 15 of the Rome Statute on the Authorization of an Investigation into the Situation in the Republic of Kenya, de fecha 31 de marzo de 2010, No ICC-01/09, pfo. 89, con más referencias; Corte Penal Internacional, Sala de Cuestiones Preliminares III, Corrigendum to "Decision Pursuant to Article 15 of the Rome Statute on the Authorisation of an Investigation into the Situation in the Republic of Côte d'Ivoire"n, de fecha 15 de noviembre de 2011, No ICC-02/11, pfo. 45; Corte Penal Internacional, Sala de Cuestiones Preliminares II, Decision on the Confirmation of Charges Pursuant to Article 61(7)(a) and (b) of the Rome Statute, de fecha 23 de enero de 2012, No ICC-01/09-01/11, pfo. 109; Corte Penal Internacional, Sala de Cuestiones Preliminares I, Decision on the confirmation of 
Estado como fuente de la política con la conjunción disyuntiva "o" el que la política provenga de agentes del Estado. De ello resulta entonces que de acuerdo a la Ley No 20.357 no se requiere que el Estado en general, en todas, una mayoría o un número considerable de sus reparticiones sea abusado para llevar adelante un ataque contra una población civil, sino que basta con que sea identificable una política de agentes del Estado, que como tales debieran respetar y hacer respetar los derechos de las personas y tienen a su disposición recursos que debieran estar destinados a ello, aparte de ser depositarios de la fe pública; todo lo cual hace especialmente grave que originen una política relevante.

Las otras dos posibilidades de origen de la política están radicadas en ciertas clases de grupos organizados. En esto, la Ley No 20.357 es más estricta que el Estatuto de Roma, de acuerdo al cual la política puede emanar de cualquier organización ${ }^{20}$. Uno de los grupos a los que se refiere la Ley No 20.357 como eventuales fuentes de la política, es a grupos armados con control sobre un territorio, con una descripción tomada del artículo

charges against Laurent Gbagbo, de fecha 12 de junio de 2014, No ICC-02/1101/11, pfo. 220.

${ }^{20}$ Una discusión inicial sobre el particular fue zanjada en tal sentido. Pueden consultarse, por todos, Werle, Gerhard - Burghard, Boris, ¿Requieren los crimenes de lesa humanidad de la participación de un Estado o de una organización "cuasiestatal"? en Cárdenas Aravena, Claudia - Fernández Neira, Karinna (editoras), La Corte Penal Internacional y sus primeros 10 años: un enfoque práctico (Santiago, Thomson Reuters, 2013), pp. 289 y ss.; Hall, Christopher Keith - Ambos, Kai, Article 7“Attack", en: Triffterer, Otto - Ambos, Kai (editores), cit. (n. 9), pp. 247 y ss.; además de Corte Penal Internacional, Sala de Cuestiones Preliminares II, Judgment pursuant to article 74 of the Statute Katanga, de fecha 7 de marzo de 2014, No ICC-01/04-01/07, pfo. 1119 y ss.; Corte Penal Internacional, Sala de Cuestiones Preliminares III, Judgment pursuant to article 74 of the Statute, de fecha 21 de marzo de 2016, No ICC-01/05-01/08, pfo. 158; Corte Penal Internacional, Sala de Cuestiones Preliminares III, Public Redacted Version of "Public Redacted Version of "Decision Pursuant to Article 15 of the Rome Statute on the Authorization of an Investigation into the Situation in the Republic of Burundi", de fecha 9 de noviembre de 2017, No ICC-01/17-X-9-US-Exp, 25 October 2017, pfo. 32; Corte Penal Internacional, Sala de Cuestiones Preliminares I, Decision on the Prosecutor's Application for the Issuance of a Warrant of Arrest for Al Hassan Ag Abdoul Aziz Ag Mohamed Ag Mahmoud, de fecha 22 de mayo de 2018, No ICC-01/12-01/18, pfo. 47 ; Corte Penal Internacional, Sala de Cuestiones Preliminares I, Rectificatif à la Décision relative à la confirmation des charges portées contre Al Hassan Ag Abdoul Aziz Ag Mohamed Ag Mahmoud, de fecha 8 de noviembre de 2019, No ICC-01/1201/18, pfo. 156; Corte Penal Internacional, Sala de Cuestiones Preliminares III, Decision Pursuant to Article 15 of the Rome Statute on the Authorisation of an Investigation into the Situation in the People's Republic of Bangladesh/Republic of the Union of Myanmar, de fecha 14 de noviembre de 2019, No ICC-01/19, pfo. 63. 
1.1 del Protocolo Adicional II, de 1977, a los Convenios de Ginebra de 1949, relativo a la protección de las víctimas de los conflictos armados sin carácter internacional ${ }^{21}$. Allí se describe, con las mismas palabras utilizadas en la ley ("grupos armados organizados que, bajo la dirección de un mando responsable, ejerzan sobre una parte de dicho territorio un control tal que les permita realizar operaciones militares") a una organización que, en caso de ser parte de un conflicto armado contra las fuerzas armadas de un Estado, hace aplicable ese protocolo. Contemporáneamente, el requisito de que cada parte controle un territorio para que sea aplicable el derecho internacional humanitario ha quedado superado (vid., a saber, el artículo 8.2 literales c)-f) del Estatuto de Roma).

La última opción se refiere a grupos organizados "que detenten un poder de hecho tal que favorezca la impunidad de sus actos". Esta característica es original del derecho chileno, y hace eco de un factor que se encuentra relevado en varias resoluciones judiciales sobre crímenes de lesa humanidad cometidos en el periodo entre septiembre de 1973 y marzo de 1990, en las cuales, en múltiples ocasiones, se ha hecho referencia a que quienes delinquieron pudieron actuar confiando en que sus conductas quedarían impunes, considerando que tal impunidad estuvo garantizada por la no interferencia en sus métodos por parte de quienes detentaban el poder, el ocultamiento de la realidad y la desinformación de la opinión pública local y extranjera ${ }^{22}$.

Ya que el listado de la ley es taxativo, la política que emane de cualquier otra fuente no bastará para considerar que existen crímenes de lesa humanidad de acuerdo al derecho chileno.

2. Lo que, por no estar definido en la Ley No 20.357, debe determinarse de acuerdo al sentido técnico de las expresiones en el derecho penal internacional,

${ }^{21}$ Un comentario puede revisarse en Comité Internacional de la Cruz Roja, Protocol Additional to the Geneva Conventions of 12 August 1949, and relating to the Protection of Victims of Non-International Armed Conflicts (Protocol II), 8 June 1977, Commentary of 1987: material field of application, >https://ihl-databases. icrc.org/applic/ihl/ihl.nsf/Treaty.xsp?action=openDocument\&documentId=D9E6 B6264D7723C3C12563CD002D6CE4<.

${ }^{22}$ Puede consultarse, a saber, Corte Suprema, sentencia de reemplazo de 7 de noviembre de 2016, rol No 35.550-2015, considerando tercero; Corte Suprema, resolución de 6 de junio de 2017, rol № 87.830-2016, considerando sexto. Más referencias en la memoria de licenciatura de MARTínez VARGAS, Antonia, La descripción del ataque generalizado y/o sistemático contra una población civil acaecido entre septiembre de 1973 y marzo de 1990 en las resoluciones judiciales chilenas sobre crimenes de lesa humanidad (2006-2019). 
en cuanto resulte compatible con las decisiones de los poderes colegisladores chilenos

Teniendo como base el marco descrito en el apartado anterior, se tratará a continuación la interpretación de las expresiones "política”, en cuanto a cómo se ha de definir su existencia, considerando las disposiciones legales; y "ataque", en particular en cuanto a la clase de conductas que cuentan para conformarlo.

\section{a) Cómo se determina la política}

La ley chilena calla respecto de qué es lo que se ha de entender como política para los efectos de los crímenes de lesa humanidad. Si bien hay referencias a la política para explicitar sus fuentes y su relación con el ataque, no se la define, lo que lleva a que deban atenderse los criterios del derecho internacional para determinar su existencia.

$\mathrm{Al}$ igual que otros términos de la Ley $\mathrm{N}^{\circ} 20.357$, en materia de crímenes de lesa humanidad, la voz "política" es un término técnico. Tradicionalmente, se ha constatado que los actos en los que consiste el ataque han sido informados por un plan o política (plan or policy). La política entonces se ha entendido tradicionalmente como aquello que conecta a los actos, haciendo que ellos sean comprensibles como algo distinto de una mera agregación de actos al azar o actos aislados ${ }^{23}$. Con el Estatuto de Roma de la Corte Penal Internacional se aprobó un texto que pone más énfasis en la política, explicitándola como un requisito del ataque contra una población civil en su artículo 7.2 a). Hay referencias para su determinación en los Elementos de los Crímenes para el artículo 7 del Estatuto de Roma, introducción, pfo. 3, y sobre todo en resoluciones judiciales, donde se han asentado ciertos criterios. Siendo las resoluciones judiciales un medio de determinación de reglas de derecho internacional (artículo 38 del Estatuto de la Corte Internacional de Justicia) corresponde tener en consideración lo que han manifestado reiteradamente para interpretar el término.

En los Elementos de los Crímenes para el artículo 7, introducción pfo. 3, se encuentra información acerca de cómo ha de manifestarse la política, al explicitarse que la fuente de la que emana la política debe promover o alentar activamente un ataque, y en la nota al pie No6 se agrega que "en circunstancias excepcionales, podría ejecutarse por medio de una omisión deliberada de actuar y que apuntase conscientemente a alentar un ataque

${ }^{23}$ Robinson, Darryl, Crimes against Humanity. A Better Policy on "Policy", en STAHN, Carsten, The Law and Practice of the International Criminal Court (Oxford, Oxford University Press, 2015), pp. 705 y ss.; Hall, Christopher Keith - Ambos, Kai, Article 7- "Attack", en: Triffterer, Otto - Ambos, Kai (editores), cit. (n. 9), p. 244 y ss. 
de ese tipo", lo que "no se puede deducir exclusivamente de la falta de acción" ${ }^{24}$. Esto último se dará claramente cuando ante la evidencia de que está teniendo lugar la comisión de actos inhumanos vinculados a un determinado curso de acción, quien tenga poder para incidir sobre él resuelva no tomar oportunamente las medidas a su alcance que tengan eficacia para modificarlo, de modo que es previsible que dicho curso de acción no cambie por si solo y se sigan cometiendo actos inhumanos. Esta conducta, siendo omisiva, alienta la comisión de crímenes, por lo que puede contar como manifestación de una política. Otras medidas, como arengar a quienes se ha imputado responsabilidad en actos inhumanos, favorecer su carrera dentro de una organización o respaldar sin matices su actuar, serían en cambio acciones que manifiestan la existencia de una política.

Diversas resoluciones de la Corte Penal Internacional se han venido refiriendo a la política como elemento típico de los crímenes de lesa humanidad. Hay consenso en que la política no requiere ser adoptada formalmente, y para probarla se puede recurrir a indicios. Para ello, se ha considerado relevante, en distintos casos, que se destinen recursos a su ejecución; que se siga un patrón regular de conducta; que el ataque sea planificado, dirigido u organizado; o que exista involucramiento de fuerzas estatales u organizadas en la comisión de los crímenes; entre otros ${ }^{25}$. Así, por ejemplo, en la situación de Libia se consideró la evidencia de que se habría ordenado a las "Fuerzas de Seguridad" disciplinar a los manifestantes, que dichas "Fuerzas de Seguridad" se encontraran desplegadas por todo el país, y que se tomaran medidas para reforzarlas frente a las manifestaciones. También se consideró relevante la información relativa a una campaña tendiente a evitar que se informara ciertos hechos y castigar a quienes lo hicieran ${ }^{26}$.

En cuanto a cómo inciden las definiciones de la Ley No 20.357 en la determinación de la política, cuando el ataque consiste en un solo acto, la única opción de que responda a una política resulta ser que su comisión obedezca a un plan. En cambio, cuando el ataque se componga de varios actos, rigen los criterios ya establecidos, de acuerdo a los cuales la política

${ }^{24}$ En un sentido análogo, STAHN, Carsten, A Critical Introduction to International Criminal Law (Cambridge, Cambridge University Press, 2019), p. 55 y ss.

${ }^{25}$ Con más detalles y referencias CÁrdenas Aravena, Claudia Marcela, El ataque contra una población civil en la práctica de la Corte Penal Internacional, en Revista de Derecho, Valdivia (aceptado para publicación, sin fecha).

${ }^{26}$ Corte Penal Internacional, Sala de Cuestiones Preliminares I, orden de detención de Saif Al-Islam Qadhafi, de fecha 27 de junio de 2011, No ICC-01/11, pfo. 28-30. 
no necesariamente ha de existir con anterioridad al ataque, pudiendo surgir conforme se van cometiendo los actos inhumanos ${ }^{27}$.

Por otra parte, cuando el ataque apunta a un grupo de personas, la política debe determinar la característica distintiva que hace a ese grupo de personas ser objeto del ataque, en tanto que si se explora la variante de que este afecte a un número considerable de personas, la política puede bien sea haberlo buscado o haberle sido indiferente que ocurra ese efecto, al no haber limitado su ejecución a medios que lo excluyan.

b) Qué actos cuentan para conformar un ataque de acuerdo al artículo 1.1 de la Ley No 20.357

Hay un aspecto fundamental respecto del cual no se manifiesta una decisión legislativa chilena que sirva de fundamento para apartarse del sentido técnico del término en el derecho penal internacional: el concerniente a qué clase de actos son los que pueden contar como parte del ataque.

El Estatuto de Roma zanja expresamente esta cuestión en la definición de ataque contra una población civil de su artículo 7.2 a), señalando que los actos que cuentan para constituir un ataque son los descritos en su artículo 7.1, que reciben el nombre genérico de "actos inhumanos". Esos actos están descritos en el artículo 7.1 del Estatuto de Roma como sigue: homicidio; exterminio; esclavitud; deportación o traslado forzoso de población; encarcelación u otra privación grave de la libertad física en violación de normas fundamentales de derecho internacional; tortura; violación, esclavitud sexual, prostitución forzada, embarazo forzado, esterilización forzada o cualquier otra forma de violencia sexual de gravedad comparable; persecución de un grupo o colectividad con identidad propia fundada en motivos universalmente reconocidos como inaceptables con arreglo al derecho internacional; desaparición forzada de personas; apartheid; y otros actos inhumanos de carácter similar que causen intencionalmente grandes sufrimientos o atenten gravemente contra la integridad física o la salud mental o física. Existen elementos que ayudan a la determinación de estas conductas tanto en el mismo tratado (art. 7.2), como en los Elementos

${ }^{27}$ Corte Penal Internacional, Sala de Cuestiones Preliminares II, Judgment pursuant to article 74 of the Statute Katanga, de fecha 7 de marzo de 2014, No ICC01/04-01/07, pfo. 1110 ; Corte Penal Internacional, Sala de Cuestiones Preliminares IV, Judgment Bosco Ntaganda, de fecha 8 de julio de 2019, No ICC-01/04-02/06, pfo. 674 . 
de los Crímenes ${ }^{28}$, en la jurisprudencia y en la doctrina del derecho penal internacional ${ }^{29}$.

Sin perjuicio de lo anterior, la Corte Penal Internacional ha entendido, en sus resoluciones, que la prueba de actos no comprendidos en el artículo 7.1 del Estatuto de Roma pueda ser considerada para otros aspectos. Por ejemplo, puede ayudar a determinar si el ataque fue dirigido contra una población civil, o se llevó adelante de conformidad con una política ${ }^{30}$.

En el derecho alemán, que tampoco tiene una definición de ataque, tanto en la doctrina como en la práctica judicial se ha establecido que las conductas que han de investigarse como potencialmente constitutivas de ataque son las descritas en el artículo 7.1 del Estatuto de Roma ${ }^{31}$.

La decisión de introducir, en el tipo del derecho interno, variaciones

${ }^{28}$ Se trata de un cuerpo normativo aprobado por la Asamblea de Estados Partes de la Corte Penal Internacional y que está previsto como ayuda interpretativa del Estatuto en su artículo 9, formando parte del derecho aplicable por la Corte de acuerdo a su artículo 21.1 .

${ }^{29}$ A saber, Werle, Gerhad - Jessberger, Florian, cit. (n. 1), p. 577 y ss., Hall, Christopher et al., Crimes against humanity, en Triffterer, Otto - Ambos, Kai (editores), cit. (n. 9), pp. 178 y ss.

${ }^{30}$ Corte Penal Internacional, Sala de Cuestiones Preliminares I, Decision on the confirmation of charges against Laurent Gbagbo, de fecha 12 de junio de 2014, No ICC-02/11-01/11, pfo. 210; Corte Penal Internacional, Sala de Cuestiones Preliminares III, Judgment pursuant to article 74 of the Statute, de fecha 21 de marzo de 2016, No ICC-01/05-01/08, pfo. 151; Corte Penal Internacional, Sala de Cuestiones Preliminares III, Public Redacted Version of "Public Redacted Version of "Decision Pursuant to Article 15 of the Rome Statute on the Authorization of an Investigation into the Situation in the Republic of Burundi", de fecha 9 de noviembre de 2017, No ICC-01/17-X-9-US-Exp, 25 October 2017, pfo. 32; Corte Penal Internacional, Sala de Cuestiones Preliminares III, Decision Pursuant to Article 15 of the Rome Statute on the Authorisation of an Investigation into the Situation in the People's Republic of Bangladesh/Republic of the Union of Myanmar, de fecha 14 de noviembre de 2019, No ICC-01/19, pfo. 63. Vid. asimismo Corte Penal Internacional, Sala de Cuestiones Preliminares II, Judgment pursuant to article 74 of the Statute Katanga, de fecha 7 de marzo de 2014, No ICC-01/04-01/07, pfo. 1101; Corte Penal Internacional, Sala de Cuestiones Preliminares IV, Judgment Bosco Ntaganda, de fecha 8 de julio de 2019, No ICC-01/04-02/06, pfo. 663; Corte Penal Internacional, Sala de Cuestiones Preliminares I, Rectificatif à la Décision relative à la confirmation des charges portées contre Al Hassan Ag Abdoul Aziz Ag Mohamed Ag Mahmoud, de fecha 8 de noviembre de 2019, No ICC-01/12-01/18, pfo. 143.

${ }^{31}$ WerLE, Gerhard, 57 Völkerstrafgesetzbuch, Verbrechen gegen die Menschlichkeit, en SAFFERING, Christoph (Bandredakteur), Münchner Kommentarzum Strafgesetzbuch, Band 8 Nebenstrafrecht III (3a edición, Beck, Munich, 2018), número marginal 14; Bundesgerichtshof, Beschluss vom 17. Juni 2010, AK 3/10, número marginal 25. Una resolución más reciente, aun refiriendo expresamente a la recién reseñada, parece asumir que se requieren multiplicidad de actos del $\$ 7$ del Código penal internacional 
en la descripción de las conductas, respecto del listado del artículo 7.1 del Estatuto de Roma, incide radicalmente en la posibilidad de imputarlas como crímenes de lesa humanidad conforme a la Ley No 20.357, en el sentido de que, si una conducta no está descrita en los artículos 3 al 9 de esa ley, no podrá imputarse a una persona por crímenes de lesa humanidad con arreglo a ella, sin perjuicio del régimen de derecho internacional aplicable. Eso podría conllevar que subsista, para algunos casos, el sistema de doble subsunción que se viene aplicando invariablemente respecto de los delitos de la última dictadura ${ }^{32}$.

Así, para que una conducta se pueda imputar como crimen de lesa humanidad de acuerdo a la Ley No 20.357 debe estar descrita entre los artículos 3 y 9 de esa ley y cometerse como parte de un ataque contra una población civil, en tanto que tal ataque estará conformado conductas, que constituyan actos inhumanos de acuerdo al derecho internacional. Eso incluye, a saber, los que impliquen someter a violaciones intencionales de derechos fundamentales a miembros de una colectividad por motivos discriminatorios inaceptables conforme al derecho internacional, la encarcelación u otra privación grave de la libertad física en violación de normas fundamentales de derecho internacional de una duración inferior a cinco días, o conductas constitutivas de apartheid.

\section{RECAPITULACIÓN}

De cara al panorama legislativo chileno, y de acuerdo a las reglas generales, para interpretar el término ataque en el artículo 1.1 de la Ley No 20.357 deben considerarse tanto las definiciones legales, que deben aplicarse donde existan, como el sentido técnico de los términos, en lo que no se vea modificado por dichas definiciones legales.

Vale decir, respecto de aquello que la ley chilena no dispone expresamente (¿qué actos cuentan como parte de un ataque? ¿cómo ha de determinarse que existe una política?), una interpretación del artículo 1.1 de la Ley No 20.357 de acuerdo a las reglas generales lleva a entender que ha de estarse a los criterios del derecho internacional. En tanto que para determinar la cantidad de actos suficientes para constituir un ataque, el

alemán, sin dar mayores explicaciones. Vid. Bundesgerichtshof, Beschluss vom 6 . Juni 2019, AK 14/19, número marginal 57.

${ }^{32}$ Vid, a saber, Gil Herrera, María Fernanda - Manzur Toro, Valentina, Crimenes de lesa humanidad. Sistematización de argumentos de los fallos emitidos por los tribunales superiores del pais (2006-2013), en >http://repositorio.uchile.cl/ bitstream/handle/2250/146365/Cr\%C3\%ADmenes-de-lesa-humanidad-en-Chile. pdf?sequence $=1<$, pp. 222 y ss. 
objeto que puede tener el ataque, las fuentes de la política y su relación con los actos que constituyen el ataque, ha de estarse a lo que expresamente dispone la Ley No 20.357.

Integrando entonces, la definición de ataque del derecho internacional con los elementos que se ven modificados por el derecho interno, el resultado puede sintetizarse como sigue: por "ataque contra una población civil" en el artículo 1.1 de la Ley No 20.357 se entenderá uno o más actos de los mencionados en el párrafo 1 del artículo 7 del Estatuto de Roma, que afecten a un número considerable de personas o se dirijan contra ellas, en respuesta a una política que puede emanar ya sea de un Estado; de agentes del Estado; de grupos armados organizados que, bajo la dirección de un mando responsable, ejerzan sobre algún territorio un control tal que les permita realizar operaciones militares; o de grupos organizados que detenten un poder de hecho tal que favorezca la impunidad de sus actos.

\section{CONSECUENCIAS PRÁCTICAS PARA LAS INVESTIGACIONES POR CRÍMENES}

\section{DE LESA HUMANIDAD}

La determinación de lo que en el artículo 1.1 de la Ley No 20.357 ha de entenderse como ataque contra una población civil impacta directamente el en alcance de las investigaciones en materia de crímenes de lesa humanidad, puesto que define el ámbito de los hechos a investigar con miras a ser probados en un proceso, para establecer, en último término, si ha existido o no una conducta punible.

De acuerdo a lo explicado en los apartados anteriores, en materia de crímenes de lesa humanidad ha de investigarse, aparte del hecho individual concreto que pretenda calificarse como crimen de lesa humanidad (por ejemplo, un homicidio), la ocurrencia de otras conductas descritas en el artículo 7.1 del Estatuto de Roma.

Esto entraña una complejidad que debiera ser adecuadamente tenida en consideración por quienes tengan a su cargo la dirección de investigaciones, ya que será necesario pesquisar dichos actos, para lo cual los criterios en los cuales normalmente se agrupa la información, a lo menos hasta donde son público por los boletines institucionales del Ministerio Público, pueden no ser los más idóneos ${ }^{33}$. Así, por ejemplo, para determinar si existe persecución como acto inhumano habrá que realizar un análisis que puede no ser familiar sin más para un(a) Fiscal, lo mismo para determinar

\footnotetext{
${ }^{33} \mathrm{http}: / /$ www.fiscaliadechile.cl/Fiscalia/estadisticas/index.do.
} 
la eventual existencia de otros actos inhumanos de carácter similar que atenten gravemente contra la integridad física o la salud mental o física ${ }^{34}$.

Por cierto, es previsible que haya supuestos en los que esto no sea especialmente relevante para la práctica. Esto ocurrirá cuando pueda determinarse la existencia de un ataque solamente en base a las conductas que el sistema usualmente pesquisa (por ejemplo, homicidio, torturas, violaciones de acuerdo a la tipificación del derecho interno), y los otros actos inhumanos que puedan eventualmente concurrir no varíen el alcance del ataque por ejemplo en cuanto al periodo que abarca o a la población contra la cual este se ha dirigido o a la cual ha afectado. En cambio, cuando los contornos del ataque solo sean adecuadamente aprehensibles, ya sea en cuanto al periodo que abarca o en cuanto a la población contra la que se dirige o a la que afecta, el asunto objeto de este trabajo sí tendrá capital relevancia práctica, pues de su comprensión y de la actuación en coherencia con esa comprensión dependerá que se pueda subsumir adecuadamente los hechos en el tipo, dando cuenta adecuada del injusto y logrando en último término, una reacción penal proporcional a la gravedad de los hechos.

\section{CONCLUSIONES}

Los crímenes de lesa humanidad tienen una estructura bipartita, en la que siempre debe concurrir un ataque generalizado o sistemático contra una población civil, como contexto de la conducta que en concreto vaya a imputarse, además de darse los requisitos de uno o más de los hechos descritos en los artículos 3 al 9 de esa ley.

Los poderes colegisladores chilenos eligieron tipificar los crímenes de lesa humanidad en una ley especial, fuera del Código penal, llevando adelante una implementación modificatoria del Estatuto de Roma, lo que implica que para la interpretación de las normas ha de tenerse en cuenta el sentido técnico de los términos del derecho internacional salvo que esté explícita una decisión legislativa diversa, caso en el cual por cierto prima esta última para los efectos del derecho interno, pues su existencia da a entender claramente que se ha querido dar un sentido diverso al que en el derecho internacional tienen ciertos términos técnicos. Una interpretación del artículo 1.1. de la Ley No 20.357 de acuerdo a las reglas generales que el derecho conoce al efecto, demanda integrar las decisiones expresadas por los poderes colegisladores chilenos en el articulado de esa misma ley.

Para determinar si cabe perseguir crímenes de lesa humanidad de acuerdo a la Ley No 20.357, debe examinarse si han existido uno o más

\footnotetext{
${ }^{34}$ Vid. nota 9.
} 
actos de los descritos en el art 7.1 del Estatuto de Roma, que afecte(n) a un número considerable de personas o esté(n) dirigidos en su contra y que responda(n) a una política ya sea de un Estado; de agentes del Estado; de grupos armados organizados que, bajo la dirección de un mando responsable, ejerzan sobre algún territorio un control tal que les permita realizar operaciones militares; o de grupos organizados que detenten un poder de hecho tal que favorezca la impunidad de sus actos.

Tener lo anterior debidamente en cuenta en las investigaciones relativas a crímenes de lesa humanidad permitirá determinar de manera adecuada si ha existido un ataque relevante a la tipificación de los crímenes de lesa humanidad en la Ley No 20.357, y sus alcances en cuanto al tiempo y en cuanto a la población afectada, lo cual a su vez permitirá calificar adecuadamente ciertos hechos individuales como crímenes de lesa humanidad, alcanzando la consecuencia deseable de una reacción penal proporcional a la gravedad del injusto.

\section{BiBLIOGRAFÍA}

IV. Convenio de Ginebra relativo a la protección debida a personas civiles en tiempo de guerra, 1949.

Alemania, Völkerstrafgesetzbuch (Código de Derecho Penal Internacional), publicada el 26 de junio de 2002.

Alija Fernández, Rosa Ana - Saura Estapà, Jaume, Towards a Single and Comprehensive Notion of 'Civilian Population' in Crimes against Humanity, en International Criminal Law Review vol. 16 (2016), pp. 1-31. DOI: https://doi. org/10.1163/15718123-01701001.

Bassiouni, M. Cherif, Crimes Against Humanity. Historical evolution and contemporary application (Cambridge, Cambridge University Press, 2011). DOI: https://doi. org/10.1017/CBO9780511976537.

Bundesgerichtshof, Beschluss vom 17. Juni 2010, AK 3/10.

Bundesgerichtshof, Beschluss vom 6. Juni 2019, AK 14/19.

Cárdenas Aravena, Claudia Marcela, Los crímenes del Estatuto de la Corte Penal Internacional en el derecho chileno, necesidad de una implementación, en Política Criminal No 2 (2006), pp. 1-17.

Cárdenas Aravena, Claudia Marcela, La aplicabilidad del derecho internacional por tribunales chilenos para interpretar la ley $\mathrm{N}^{\circ} 20.357$, en Revista de Derecho, Coquimbo (2013), pp. 121-145. DOI: http://dx.doi.org/10.4067/S071897532013000200005.

Cárdenas Aravena, Claudia Marcela, Los crimenes de lesa humanidad en el derecho chileno y en el derecho internacional. Sus requisitos comunes, además de referencias a los actos inhumanos en particular, en Revista de Derecho, Valdivia (2014), pp. 69-89. DOI: http://dx.doi.org/10.4067/S0718-09502014000200008.

Cárdenas Aravena, Claudia Marcela, El ataque contra una población civil en la práctica de la Corte Penal Internacional, en Revista de Derecho, Valdivia (aceptado para publicación, sin fecha). 
Comité Internacional de la Cruz Roja, Protocol Additional to the Geneva Conventions of 12 August 1949, and relating to the Protection of Victims of Non-International Armed Conflicts (Protocol II), 8 June 1977, Commentary of 1987: material field of application, >https://ihldatabases.icrc.org/applic/ihl/ nsf/Treaty.xsp? - action=openDocument\&documentId=D9E6B6264D7723C3 C12563CD002D6CE4<.

Chile, Código Civil. D.F.L. 1, fija el texto refundido, coordinado y sistematizado del Código Civil y otras leyes. Diario Oficial, 16 de mayo de 2000.

Chile, Código Penal. Diario Oficial, 12 de noviembre de 1874.

Chile, Ley No 20.359, tipifica crímenes de lesa humanidad, de genocidio y crímenes y delitos de guerra. Diario Oficial, 18 de julio de 2009.

De Brouwer, Anne Marie, Supranational Prosecution of Sexual Violence. The ICC and the Practice of the ICTY and the ICTR, (Intersentia, Antwerpen-Oxford).

Евое Osuj, Chile, Crimes Against Humanity: Directing Attacks Against A Civilian Population, en African Journal of Legal Studies (2008), pp. 118-129. DOI: https:// doi.org/10.1163/221097312X13397499736543.

España, Código Penal. BOE, 24 de noviembre de 1995.

Gil Herrera, María Fernanda - Manzur Toro, Valentina, Crímenes de lesa humanidad. Sistematización de argumentos de los fallos emitidos por los tribunales superiores del pais (2006-2013), en >http://repositorio.uchile.cl/bitstream/handle/2250/146365/

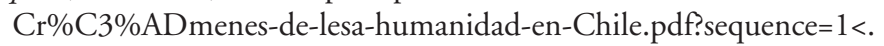

Hall, Christopher et al., Article 7, Crimes Against Humanity, en TriffTerer, Otto - Aмвоs, Kai (editores), The Rome Statute of the International Criminal Court, A Commentary ( $3^{a}$ edición, Munich, Beck, Nomos, Hart, 2016), pp. 144-294. DOI: https://doi.org/10.5771/9783845263571.

London Agreement of August 8th 1945. Anexo: Estatuto del Tribunal Militar Internacional de Nuremberg, 1945.

Martínez VARGas, Antonia, La descripción del ataque generalizado y/o sistemático contra una población civil acaecido entre septiembre de 1973 y marzo de 1990 en las resoluciones judiciales chilenas sobre crimenes de lesa humanidad (2006-2019).

Protocolo Adicional a los Convenios de Ginebra del 12 de agosto de 1949 relativo a la protección de las víctimas de los conflictos armados sin carácter internacional (Protocolo II, de 1977).

Robinson, Darryl, Crimes against Humanity. A Better Policy on "Policy", en STaHn, Carsten, The Law and Practice of the International Criminal Court (Oxford, Oxford University Press, 2015), pp. 705-731.

SADAT, Leila Nadya, Putting Peacetime First: Crimes against Humanity and the Civilian Population Requirement, en Emory International Law Review, vol. 31 (2017), pp. 197-269.

SAFFERLING, Christoph, Internationales Strafrecht (Springer, Heidelberg, 2011).

STAHN, Carsten, A Critical Introduction to International Criminal Law (Cambridge, Cambridge University Press, 2019).

Werle, Gerhard - Burghard, Boris, ¿Requieren los crimenes de lesa humanidad de la participación de un Estado o de una organización "cuasiestatal"? en CÁRDENAS Aravena, Claudia - Fernández Neira, Karinna (editoras), La Corte Penal Internacional y sus primeros 10 años: un enfoque práctico (Santiago, Thomson Reuters, 2013), pp. 289-309. 
Werle, Gerhard - Jessberger, Florian, Tratado de derecho penal internacional (3a edición, Valencia, Tirant lo Blanch, 2017).

WerLe, Gerhard, $\$ 7$ Verbrechen gegen die Menschlichkeit, en SAFFERING, Christoph (Bandredakteur), Münchner Kommentar zum Strafgesetzbuch, Band 8 Nebenstrafrecht III ( $3^{a}$ edición Beck, Munich, 2018).

Werle, Gerhard, Das Völkerstrafgesetzbuch, en JuristenZeitung (15/16 2002), pp. 725-734.

WerLE, Gerhard, Konturen enies deutschen Völkerstrafrechts, en JuristenZeitung (18 2001), pp. 885-895.

\section{JURISPRUDENCIA CITADA}

Corte Penal Internacional, Sala de Cuestiones Preliminares I, Decision on the confirmation of charges against Laurent Gbagbo, de fecha 12 de junio de 2014, No ICC-02/11-01/11.

Corte Penal Internacional, Sala de Cuestiones Preliminares I, Decision on the Prosecutor's Application for the Issuance of a Warrant of Arrest for Al Hassan Ag Abdoul Aziz Ag Mohamed Ag Mahmoud, de fecha 22 de mayo de 2018, No ICC-01/12-01/18.

Corte Penal Internacional, Sala de Cuestiones Preliminares I, orden de detención de Saif Al-Islam Qadhafi, de fecha 27 de junio de 2011, No ICC-01/11.

Corte Penal Internacional, Sala de Cuestiones Preliminares I, Rectificatif à la Décision relative à la confirmation des charges portées contre $\mathrm{Al} \mathrm{Hassan} \mathrm{Ag}$ Abdoul Aziz Ag Mohamed Ag Mahmoud, de fecha 8 de noviembre de 2019, No ICC-01/12-01/18.

Corte Penal Internacional, Sala de Cuestiones Preliminares II, Decision Pursuant to Article 61(7)(a) and (b) of the Rome Statute on the Charges of the Prosecutor Against Jean-Pierre Bemba Gombo, de fecha 15 de julio de 2009, No ICC-01/05-01/08.

Corte Penal Internacional, Sala de Cuestiones Preliminares II, Decision Pursuant to Article 15 of the Rome Statute on the Authorization of an Investigation into the Situation in the Republic of Kenya, de fecha 31 de marzo de 2010, No ICC-01/09.

Corte Penal Internacional, Sala de Cuestiones Preliminares II, Decision on the Confirmation of Charges Pursuant to Article 61(7)(a) and (b) of the Rome Statute, de fecha 23 de enero de 2012, No ICC-01/09-01/11.

Corte Penal Internacional, Sala de Cuestiones Preliminares II, Judgment pursuant to article 74 of the Statute Katanga, de fecha 7 de marzo de 2014, No ICC-01/04$01 / 07$.

Corte Penal Internacional, Sala de Cuestiones Preliminares III, Corrigendum to "Decision Pursuant to Article 15 of the Rome Statute on the Authorisation of an Investigation into the Situation in the Republic of Côte d'Ivoire", de fecha 15 de noviembre de 2011, No ICC-02/11.

Corte Penal Internacional, Sala de Cuestiones Preliminares III, Decision on the Prosecutor's Application Pursuant to Article 58 for a warrant of arrest against Laurent Koudou Gbagbo, de fecha 30 de noviembre de 2011, No ICC-02/11-01/11.

Corte Penal Internacional, Sala de Cuestiones Preliminares III, Decision Pursuant to Article 15 of the Rome Statute on the Authorisation of an Investigation into the Situation in the People's Republic of Bangladesh/Republic of the Union of Myanmar, de fecha 14 de noviembre de 2019, No ICC-01/19. 
Corte Penal Internacional, Sala de Cuestiones Preliminares III, Judgment pursuant to article 74 of the Statute, de fecha 21 de marzo de 2016, No ICC-01/05-01/08. Corte Penal Internacional, Sala de Cuestiones Preliminares III, Public Redacted Version of "Public Redacted Version of "Decision Pursuant to Article 15 of the Rome Statute on the Authorization of an Investigation into the Situation in the Republic of Burundi”, de fecha 9 de noviembre de 2017, No ICC-01/17-X-9US-Exp, 25 October 2017.

Corte Penal Internacional, Sala de Cuestiones Preliminares IV, Judgment Bosco Ntaganda, de fecha 8 de julio de 2019, No ICC-01/04-02/06.

Corte Suprema, resolución de 6 de junio de 2017, rol N 87.830-2016.

Corte Suprema, sentencia de reemplazo de 24 de agosto de 2015, rol № 29.086-2014.

Corte Suprema, sentencia de reemplazo de 7 de noviembre de 2016, rol No 35.5502015. 